\title{
Preface
}

\section{WHY THIS BOOK?}

Decisions prohibiting mergers always make the headlines. In practice, they are rare. The European Commission, for example, imposes remedies about ten times more often. Merger remedies are not only much more frequent; they are also more complex: predicting with reasonable certainty which elements will restore competition after completion of a merger and its related remedies is often a challenge. The concerns and the toolkits used when devising and monitoring remedies are close to those used in the regulatory field, for example when a public authority privatizes a state-owned (monopoly) business or auctions licences for new activities. Merger remedies can therefore blur the distinction between competition policy, regulatory policy and industrial policy. They can influence to different degrees the structure and performance, and hence competitiveness, of the industries concerned.

Until recently, however, merger remedies have remained a neglected area. Inside the European Commission, we were encouraged to investigate the subject, following up on a seminar co-organized in 2002 by the French Ecole des Mines and the University of California Law School on the differences between US and EC approaches to merger remedies. One of the audience's key messages was that the European Commission had to perform an ex post study comparable to the one performed by the US Federal Trade Commission (FTC) in 1996-99. After this conference, two departments of the European Commission took a particular interest in the topic. DG Enterprise tendered a study which Stephen Davies and Bruce Lyons won in the summer of 2002. Their proposal was interesting because they wanted to apply simulation techniques to merger remedies. At the same time, DG Competition started preparing its first ex post merger remedies study, which was published in late 2005. It looked at a sample of about 100 remedies decided in the years 1996-2000. I was seconded on a part-time basis from DG Enterprise to join the team and keep open a two-way channel between the projects: Davies and Lyons provided academic advice for that study and benefited from input of the study team.

This book is the result of intensive collaboration between industry experts and competition experts within the European Commission and in 
the firms concerned. This collaboration has ensured access to market participants and key information, with due respect for their confidentiality concerns.

\section{WHAT'S IN THE BOOK?}

Beyond a concise and critical review of the relevant literature, the 'main course' is Davies and Lyons's proposed practical methodology for a competition authority to assess merger remedies. The authors recommend using what they call the 'basic' simulation methodology. They explain it clearly and apply it to merger remedies in seven merger cases which they assess critically. This assessment is put into perspective by a useful competitiveness analysis of the two industry sectors in which these mergers took place, that is, the pharmaceuticals and paper industries.

The authors recommend using a simplified simulation methodology. The focus is not so much on using one or another mathematical model, but on asking a few fundamental questions about the relevant market, the nature of competition among the firms in this market, demand elasticities, and claimed efficiency savings: what would have happened post-merger, had the remedy not been imposed; and what can be expected to happen postremedy. These questions are not new but should be answered anyway.

Davies and Lyons are not 'extremists' of simulation techniques: their methodology enables them to ask the right questions and collect the right data from the start of the investigation. For them, the output of the simulations is almost secondary to this task and the data collection process. They also acknowledge that simulation techniques may appear too sophisticated, ill adapted to the tight deadlines of merger appraisal and useful only for certain 'structural' remedies (with a clean break) in horizontal mergers taking place in rather stable or mature markets. This leaves outside vertical and conglomerate mergers and the often related 'behavioural' remedies, as well as sectors with strong buyer power or strong regulator influence. Nevertheless, it remains applicable in a majority of the cases.

The authors also recognize the 'price to pay', in terms of (legal) certainty. If less weight were attached to market shares, firms would be far less able to 'read' in advance the Commission's likely response to any particular merger. Their view is that this is a price worth paying in return for an effective, effects-based analysis, and hence a more efficient merger policy. Readers will judge for themselves.

Davies and Lyons conclude with a set of policy recommendations for the European Commission as competition authority in designing remedies. 
For example, they challenge the preference for structural remedies where remedies are limited to national markets but the merger is worldwide. Behavioural remedies might be better in these national markets, especially if a national authority or a trustee can monitor the parties' compliance with their commitments, such as price commitments.

\section{APPRAISAL OF THE BOOK}

Most studies commissioned by the European Commission are not turned into a book. The fact that it has happened in this case is a tribute to the quality of the authors' work, and to their perseverance. Both are outstanding economists who combine sound academic knowledge, real-life experience and an excellent written style, all typical of their Centre for Competition Policy at the University of East Anglia.

Several colleagues in the Commission, like the authors, spent more time on this project than originally expected. Indeed, one of our tasks as 'reviewers' was to ensure that it would also be understandable by readers who do not have a $\mathrm{PhD}$ in economics or econometrics. Quite a few colleagues in the Commission took part in 'steering' the study: Geneviève Pons-Deladrière, Geert Dancet, Carles Esteva Mosso, Alexander Kopke, Stefano Vannini, Miguel de la Mano, Juergen Foecking, Thomas Heynisch and Joan Salmurri Trinxet. This collective effort certainly contributed to its quality, in my - somewhat biased - view.

This book provides a useful guide to applying simulation techniques in merger appraisal, recognizing fairly the limitations of that approach: basic simulation is not a well-developed science; it involves much judgement and uncertainty. Also, merger simulation needs to be designed in careful consideration of what it is possible to perform (from data gathering to material performance of the exercise) within the tight timescale of the proceedings, and in this respect the book takes a reasonable approach.

If I may add a critical note, the authors identify the limitations of the effectiveness criteria used by both the FTC in its 1999 study (is the buyer still in business 12 months after divestiture?) and by DG Competition in its 2005 study (a qualitative multi-factor assessment), but they themselves do not provide a better, systematic benchmark to evaluate the outcome of merger remedies. This is of course not an easy matter.

Lastly, their methodology provides a useful integrated approach to analyse the intricate trade-offs between claimed merger efficiencies and remedies. This may help to preserve welfare-enhancing mergers. 


\section{THE BOOK'S AUDIENCE}

The book is meant for practitioners and academicians interested in antitrust remedies, merger control policy in general, merger simulation techniques, merger analysis in the pharmaceuticals and paper industries and, last but not least, merger remedies.

\section{THE BOOK'S TIMING}

The book is being published at a time when the Commission has adopted a new merger remedies' notice and modified its implementing rules of the Merger Regulation. These revisions draw extensively on the results of the merger remedies study of DG Competition and the Commission's practice. This book appears at a time when a new merger wave is ongoing and is also affecting the two selected industrial sectors: pharmaceuticals and paper (pulp, paper and board) industries. The lessons that it draws from the seven cases studied remain valid. There is, for obvious reasons, very little casespecific information in the public domain; this is another advantage of the book.

Furthermore, Davies and Lyons have developed and updated most parts of the manuscript, which was submitted in 2005 as a study report to the European Commission, especially the methodological and analytical parts.

Whenever the current merger wave declines, I can only hope that the Commission will find the resources to look again ex post at the way imposed remedies have worked in practice, perhaps with a similar approach to the one adopted in this case: combining an in-house stocktaking exercise and practical experience with independent academic input.

Damien Levie 
Stephen Davies and Bruce Lyons - 9781847209979 Downloaded from PubFactory at 04/25/2023 11:14:43PM 